\title{
Cyclic Voltammetric Investigation of Caffeine at Methyl Orange Modified Carbon Paste Electrode
}

\author{
C Raril and JG Manjunatha* \\ *Department of Chemistry, Mangalore University Constituent College, India
}

Received: 阱: September 24, 2018; Published: 制 September 28, 2018

*Corresponding author: JG Manjunatha, Department of Chemistry, FMKMC College, Madikeri, Mangalore University Constituent College, Karnataka, India

\begin{abstract}
A simple, low cost, sensitive, a selective electrochemical method for the detection of caffeine (CA) was developed using polymethyl orange modified carbon paste electrode (PMO/CPE) by cyclic voltammetry (CV). It was found that caffeine shows well defined irreversible oxidation peak at $1350 \mathrm{mV}$ Vs. Calomel electrode in $0.2 \mathrm{M}$ PBS (pH 3.0) The effect of pH, Scan rate and concentration on the voltammetric response of caffeine were studied. The linear range of peak current on the concentration of caffeine in the range from $1 \times 10^{-5}$ to $5 \times 10^{-5}$ and $6 \times 10^{-5}$ to $1.5 \times 10^{-4} \mathrm{M}$ with a low detection limit of $5.7 \times 10^{-7} \mathrm{M}$ and modified electrode shows a good reproducibility with a relative standard deviation of $4.16 \%$. The PMO/CPE electrochemical sensor showed better electrocatalytic activity compared to the bare carbon paste electrode (BCPE).
\end{abstract}

Keywords: Caffeine; Carbon paste electrode; Cyclic Voltammetry; Methyl orange

\section{Introduction}

CA [1] is one of the most often used drugs. It is a naturally occurring substance found in tea leaves, kola nuts, cocoa beans, etc. with a bitter taste. It is a white crystalline alkaloid $(1,3$, 7-trimethylxanthine) and it stimulates the central nervous system causing alertness. After consuming CA within minutes, the body will absorb and reaches to the brain. It also increases blood pressure, stimulating gastric secretion and increase respiration cycles. CA can cause headaches, irritability, anxiety, drowsiness, dizziness, etc. [2-4]. Some people use CA for asthma, gallbladder diseases, shortness of breath in newborns and used for weight loss [5]. CA is one of the most commonly used stimulants among the athletes. CA creams are applied to the skin to reduce redness and itching in dermatitis. Many various analytical methods have been used for the determination of CA such as High-performance liquid chromatography [6-7] Capillary chromatography [8-9], spectroscopy [10-11], electrochemical [12-13] and FTIR [14].

The developing an effective method for the detection of CA becomes an active in the field of research. Among the different methods are developed electroanalytical method having more advantageous and become the most popular method. There are few methods are reported for the electrochemical detection of CA by using modified electrodes which includes boron-doped diamond electrodes, molecularly imprinted polymer modified carbon paste electrode, carbon fiber ultramicroelectrodes, and polymer modified glassy carbon electrode. Chemically modified electrode
[15-21] shows excellent sensitivity and selectivity and used for the determination of CA in beverages. In recent years carbon materials were widely used due to the broad potential window, rich surface chemistry, relatively easy electrode preparation, and low cost. The modification of the electrode surface becomes more popular in the field of electrochemistry because it can provide new and exciting properties.

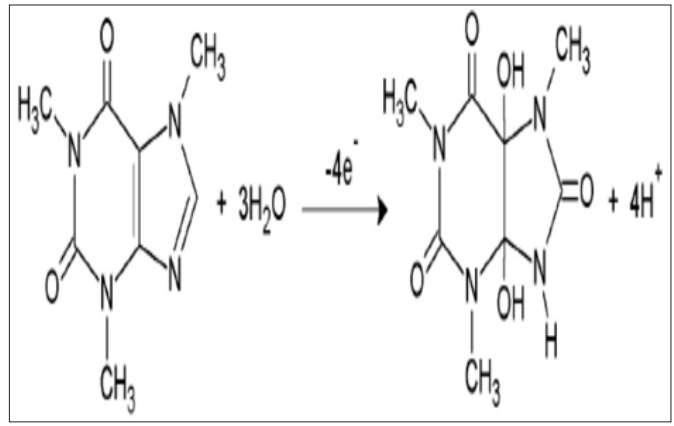

Figure 1: Scheme of oxidation mechanism of CA.

In this paper, for the first time, we reported the electrochemical determination of CA by PMO/CPE by CV techniques in $0.2 \mathrm{M}$ PBS having $\mathrm{pH}$ 3.0. The oxidation peak current of CA increased at the modified electrode suggesting the improvement of determining the sensitivity. No literature was reported on the voltammetric method for the determination of CA at PMO/CPE. The oxidation mechanism 
of CA was explained in Figure 1. The first step is a $2 \mathrm{e}^{-}, 2 \mathrm{H}^{+}$oxidation of the $\mathrm{C}-8$ to $\mathrm{N}-9$ bond to give the substituted uric acid, followed by an immediate $2 \mathrm{e}^{-}, 2 \mathrm{H}^{+}$oxidation to the 4,5 -diol analog of uric acid. The full oxidation mechanism involving overall $4 \mathrm{e}^{-}$and $4 \mathrm{H}^{+}$[22-25].

\section{Experimental}

\section{Reagents and Solutions}

Graphite, silicone oil and MO were purchased from nice chemical Pvt. Ltd. Cochin, India, CA was purchased from MolyChem. The phosphate buffer solution ( $0.2 \mathrm{M})$ was made by mixing appropriate amount $0.2 \mathrm{M}$ of monosodium dihydrogen phosphate $\left(\mathrm{NaH}_{2} \mathrm{PO}_{4}\right)$ and disodium hydrogen phosphate $\left(\mathrm{Na}_{2} \mathrm{HPO}_{4}\right)$ and was purchased from Himedia Laboratories Pvt. Ltd. and the stock solution of MO and CA $\left(25 \times 10^{-4} \mathrm{M}\right)$ and was prepared in distilled water. All the experiments were carried out at under room temperature $(25 \pm$ $\left.1^{\circ} \mathrm{C}\right)$.

\section{Instrumentation}

A three - electrode system (EA-201 Electrochemical workstation, Mumbai, India) was used for investigating the electrochemical performance of the bare and modified electrode. CV and Differential pulse voltammetry (DPV) were used for evaluating the electrochemical performance $\mathrm{CA}$ at bare and modified electrode in 0.2 M PBS ( $\mathrm{pH}$ 3.0). The bare and modified electrode was used as the working electrode, a saturated calomel electrode as the reference electrode and pt. wire as counter electrode. CV experiment was conducted at the scan rate of $100 \mathrm{mV} / \mathrm{s}$ in the potential window from $800 \mathrm{mV}$ to $1650 \mathrm{mV}$, and the DPV was conducted in the same potential window at the scan rate of 50 $\mathrm{mV} / \mathrm{s}$ with the pulse amplitude of $20 \mathrm{mV}$. Digital $\mathrm{pH}$ meter, model EQ-610 was used to make the solution the having an appropriate $\mathrm{pH}$ for the experiment.

\section{Development of BCPE and PMO/CPE}

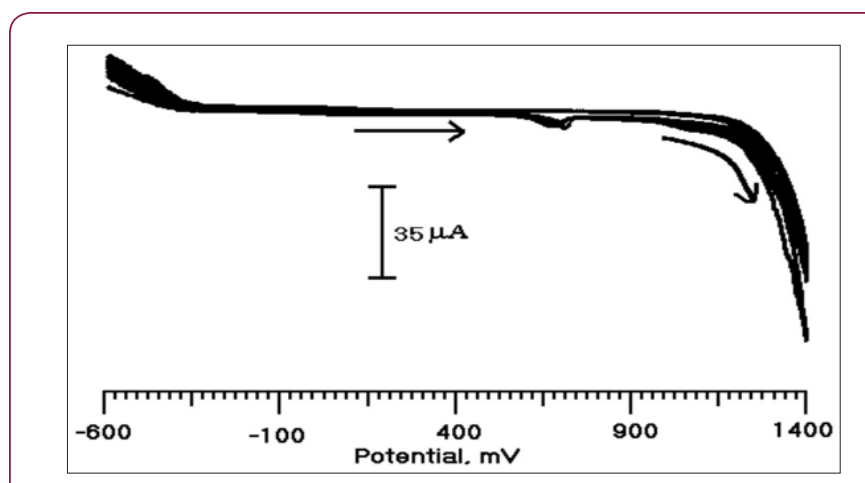

Figure 2: Cyclic voltammogram for the electro polymerzation of $1 \times 10^{-4} \mathrm{M} \mathrm{MO}$ at BCPE in $0.2 \mathrm{M}$ PBS $(\mathrm{pH}$ $7.0)$ at the scan rate of $100 \mathrm{mV} / \mathrm{s}$.

BCPE was prepared by mixing graphite powder $70 \%$ and silicone oil $30 \%$ in an agate mortar until to get a homogeneous mixture. Then the paste was packed in the end of a Teflon tube having $3 \mathrm{~mm}$ diameter. Electrical contact is provided by inserting a copper wire. The electrodeposition of PMO on to the CPE was conducted at a scan rate of $100 \mathrm{mV} / \mathrm{s}$ in the potential window from $-600 \mathrm{mV}$ to $1400 \mathrm{mV}$ Vs. SCE for 10 cycles in $0.2 \mathrm{M}$ PBS (pH 7.0)
(Figure 2) and the monomer concentration was $1 \times 10^{-4} \mathrm{M}$. After electrodepositing the electrode was washed with distilled water and was used for the electrochemical studies of CA.

\section{Result and Discussion}

\section{Cyclic Voltammetric Investigation}

Figure 3 shows the cyclic voltammetric behavior of PMO/CPE in the presence of CA $\left(2 \times 10^{-4} \mathrm{M}\right)$ and without CA in $0.2 \mathrm{M} \mathrm{PBS}(\mathrm{pH} 3.0)$. From the figure, it is clear that $\mathrm{CA}\left(2 \times 10^{-4} \mathrm{M}\right)$ undergoes oxidation at $1350 \mathrm{mV}$ (dashed line) and shows that the irreversible nature of CA at the modified electrode, but in the absence of CA (solid line) there is no oxidation peak was observed. The result shows that the strong electrocatalytic effect of CA on PMO/CPE. CA is an electroactive species that undergo oxidation. Figure 4 shows the typical CVs of CA at BCPE (solid line) and PMO/CPE (dashed line). Modified electrode shows a clear peak at $1350 \mathrm{mV}$ which is corresponding to the oxidation of CA. The appearance of the oxidative peak with a relatively larger peak current and improved peak potential at the PMO/CPE compared with the BCPE. The absence of a reductive peak indicated that CA undergoes irreversible oxidation at PMO/ CPE which is an agreement with previously reported work [2628]. Showed that the better electrocatalytic activity of CA at the modified electrode which may be due to an increased electrode surface area and improved electron exchange making suitable for CA analysis [29].

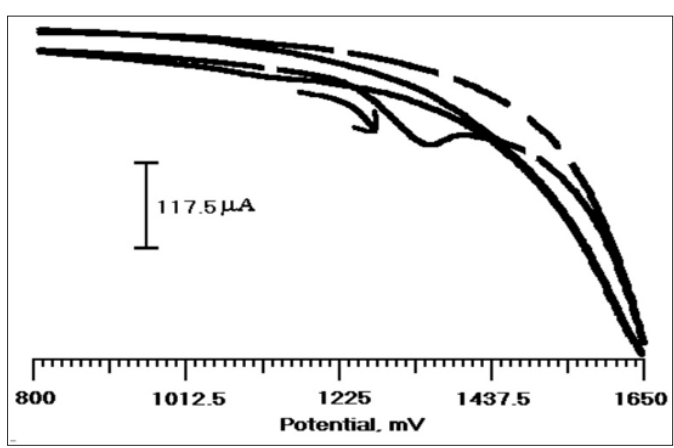

Figure 3: Cylic voltammogram of CA $\left(2 \times 10^{-4} \mathrm{M}\right)$ with (dashed line) and without (solid line) at PMO/CPE in 0.2 M PBS (pH 3.0) at the scan rate of $100 \mathrm{mV} / \mathrm{s}$.

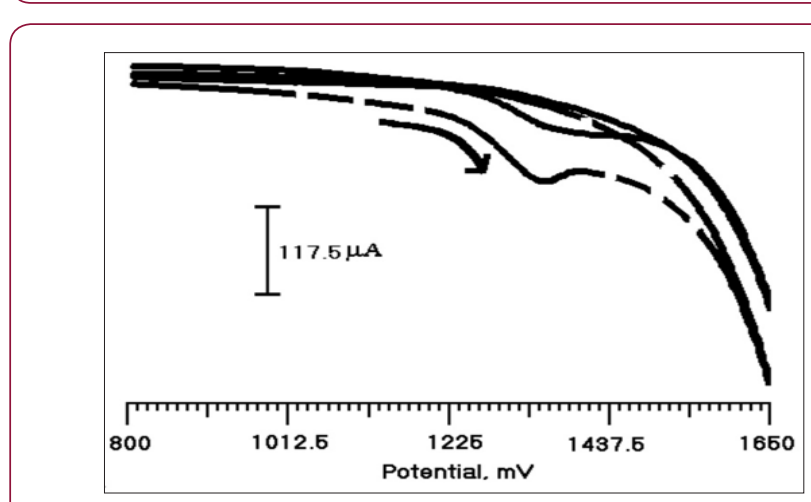

Figure 4: Cyclic voltammogram of CA $\left(2 \times 10^{-4} \mathrm{M}\right)$ in $0.2 \mathrm{M}$ PBS (pH 3.0) at BCPE (solid line) and PMO/CPE (dashed line) at the scan rate of $100 \mathrm{mV} / \mathrm{s}$. 


\section{Effect of Scan Rate}

The effect of scan rate was carried out to demonstrate whether the reaction is adsorption or diffusion controlled. The effect of scan rate on the anodic peak potential and peak current of CA at the PMO/CPE was examined by $\mathrm{CV}$ by various scan rates. Figure 5 a shows the CVs of CA $\left(2 \times 10^{-4} \mathrm{M}\right)$ at PMO/CPE in $0.2 \mathrm{M}$ PBS $(\mathrm{pH}$ $3.0)$ at various scan rates. The anodic peak current increased as the scan rate increases from 100 to $300 \mathrm{mV} / \mathrm{s}$ and the peak potential towards more negative value, confirming the irreversibility of the oxidation reaction of CA at the modified electrode. Peak current and the square root of scan rate show a linear relationship with the regression equation of $I_{p a}(\mu A)=86.96+0.54 \mathrm{v}^{1 / 2}\left(\mathrm{mVs}^{-1}\right)^{1 / 2}$ (Figure $5 b)$ with the correlation coefficient of 0.992 . Indicates that the oxidation of CA at PMO/CPE follows diffusion controlled which is agreement with reported work [30].

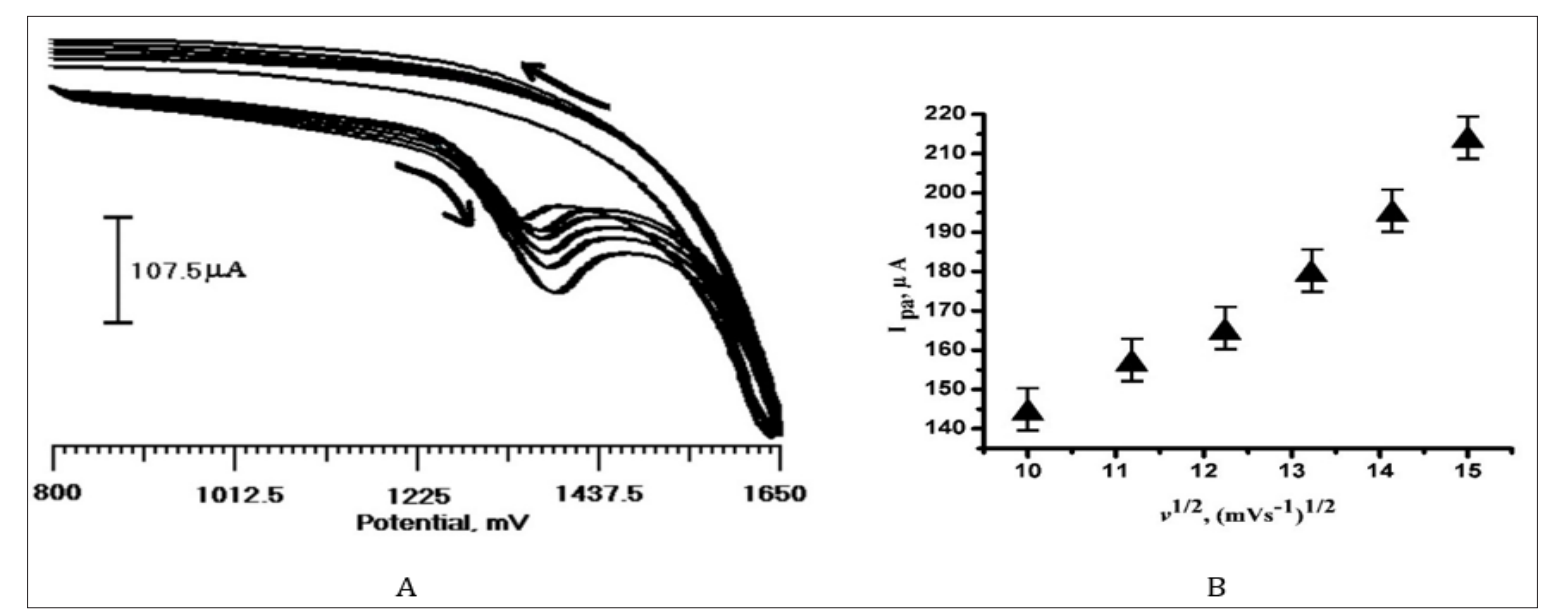

Figure 5: (a) Cyclic voltammogram of CA $\left(2 \times 10^{-4} \mathrm{M}\right)$ at PMO/CPE in $0.2 \mathrm{M}$ PBS at different scan rates $(100,125,150,175,200$, 225),

(b) $\mathrm{I}_{\mathrm{pa}} \mathrm{Vs}$ v1/2.

\section{Influence of $\mathrm{pH}$}

Figure 6a Shows the CV of CA at PMO/CPE in different $\mathrm{pH}$ (3.0 to 5.0) values in the potential window $800 \mathrm{mV}$ to $1650 \mathrm{mV}$ in $0.2 \mathrm{M} \mathrm{PBS}$ at the scan rate of $100 \mathrm{mV} / \mathrm{s}$. Oxidation peak current decreased as the $\mathrm{pH}$ increased from 3.0 to 5.0. Shows a linear relationship between Epa Vs. pH with the regression equation of Epa $(\mathrm{mV})=1368.2-6 \mathrm{pH}$ (Figure 6b). This decrease is attributed to the poor mass transport of CA at PMO/CPE at higher $\mathrm{pH}$. The plot of $\mathrm{pH}$ Vs. Ipa (Figure 6c) clearly shows the effect of $\mathrm{pH}$ on the peak current of CA. As the $\mathrm{pH}$ varies the interaction of CA at PMO/CPE changes continuously. It was observed that the anodic Peak current was optimum when the solution having $\mathrm{pH}$ of 3.0 because of the effective interaction between PMO/CPE and CA. Thus pH 3.0 was used for the whole experiment.

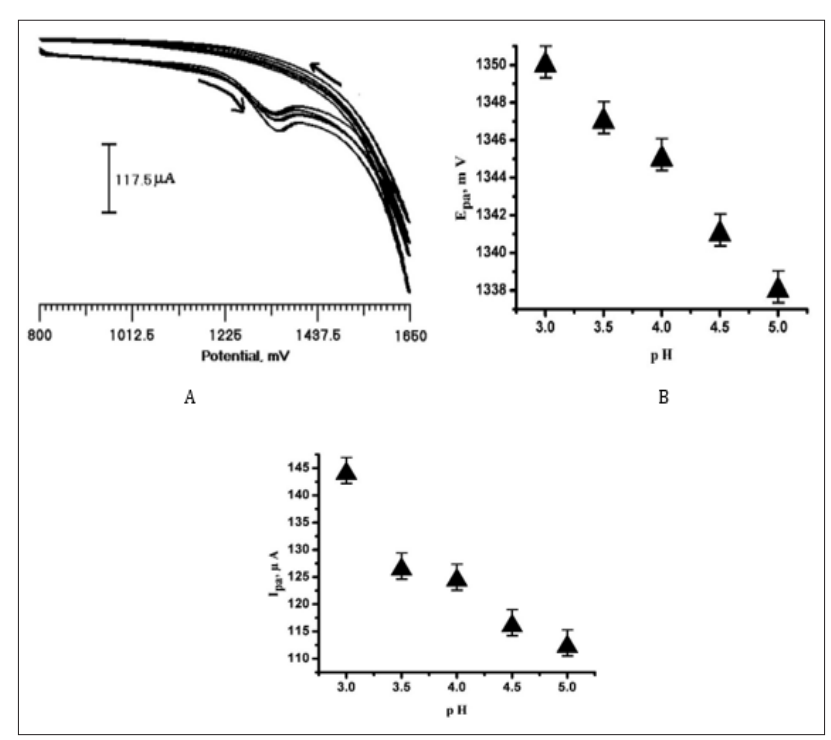

Figure 6: (a) cyclic voltammogram of CA $\left(2 \times 10^{-4} \mathrm{M}\right)$ at PMO/CPE in $0.2 \mathrm{M}$ PBS at different $\mathrm{pH}$ values 3.0, 3.5, 4.0, 4.5, 5.0 at the scan rate of $100 \mathrm{mV} / \mathrm{s},(\mathrm{b}) \mathrm{E}_{\mathrm{pa}} \mathrm{Vs} \mathrm{pH},(\mathrm{c}) \mathrm{I}_{\mathrm{pa}} \mathrm{Vs} \mathrm{pH}$. 


\section{Calibration Plot}

$\mathrm{CV}$ method was used to determine the concentration effect of CA at PMO/CPE. The plot of peak current Vs. CA concentration consisted of two linear segments $1 \times 10^{-5}$ to $5 \times 10^{-5}$ and $6 \times 10^{-5}$ to $1.5 \times 10^{-4} \mathrm{M}$, with the regression equation of Ipa $(\mathrm{A})=7.02 \times 10^{-5}+2.0$ $\mathrm{C}(\mathrm{M})$ and Ipa $=1.45 \times 10^{-4}+0.58 \mathrm{C}(\mathrm{M})$ (Figure 7). The decrease in the sensitivity of the second linear segment is likely due to the kinetic limitation [31]. The detection limit (LOD=3S/M; where $\mathrm{S}$ is the blank standard deviation for $\mathrm{n}=5$ and $\mathrm{M}$ is the slope of calibration plot) [32-34] of CA was found to be $5.7 \times 10^{-7} \mathrm{M}$. Table 1 shows the comparison of linear range and detection limit between $\mathrm{PMO} / \mathrm{CPE}$ with the other electrodes. Comparison of CA sensor constructed with various electrode materials was tabulated in the Table 1 [3539].

Table 1: Comparison of CA sensor constructed with various electrode materials.

\begin{tabular}{|c|c|c|c|c|}
\hline Electrode & Technique & Detection limit (M) & Linear range $(\mathrm{M})$ & Reference \\
\hline Boron doped diamond film electrode & DPV & $1.6 \times 10^{-7}$ & $1 \times 10^{-6}-1 \times 10^{-3}$ & 35 \\
\hline Molecularly imprinted polymer (MIP) & DPV & $1.5 \times 10^{-8}$ & $6 \times 10^{-8}-25 \times 10^{-6}$ & 36 \\
\hline Pseudo carbon paste electrode & Square wave voltammetry & $3.0 \times 10^{-7}$ & $1 \times 10^{-6}-1 \times 10^{-3}$ & 37 \\
\hline $\begin{array}{l}\text { Situ surfactant-modified Adsorptive Multi-walled } \\
\text { cabon nanotube paste electrode }\end{array}$ & Adsorptive stipping DPV & $8.8 \times 10^{-8}$ & $29 \times 10^{-8}-62.7 \times 10^{-6}$ & 38 \\
\hline $\begin{array}{l}\text { MWCNTs-poly-4-vinylpyridine composite modified } \\
\text { electrode }\end{array}$ & DPV & $1.19 \times 10^{-9}$ & $6 \times 10^{-8}-2 \times 10^{-4}$ & 39 \\
\hline Poly methyl orange modified carbon paste electrode & $\mathrm{CV}$ & $5.7 \times 10^{-7}$ & $\begin{array}{l}1 \times 10^{-5} \text { to } 5 \times 10^{-5} \text { and } 6 \times 10^{-5} \\
\text { to } 1.5 \times 10^{-4}\end{array}$ & This work \\
\hline
\end{tabular}

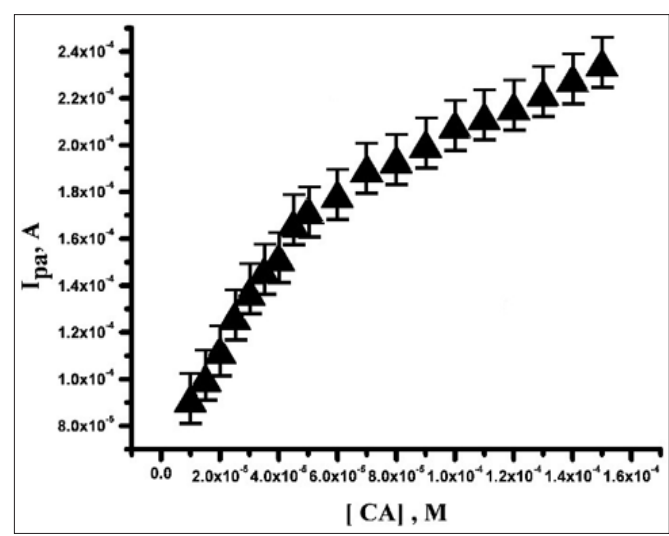

Figure 7: Calibration plot for the determination of $\mathrm{CA}$ at PMO/CPE in 0.2 M PBS (pH 3.0) at the scan rate of 100 $\mathrm{mV} / \mathrm{s}$.

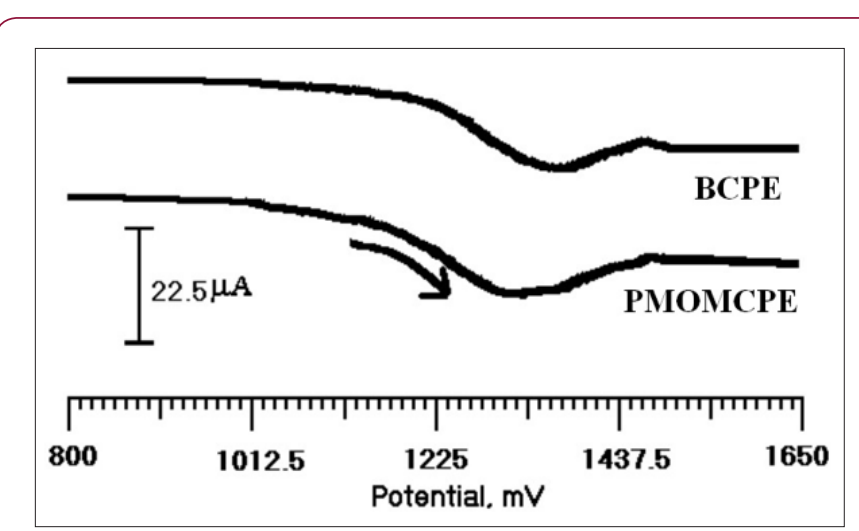

Figure 8: DPV of a solution containing CA $\left(2 \times 10^{-4} \mathrm{M}\right)$ in $0.2 \mathrm{M}$ PBS (pH 3.0) at the BCPE and PMOMCPE.

\section{Electrochemical Determination of CA by DPV}

Under optimized condition, DPV was carried out in the potential from 800 to $1650 \mathrm{mV}$ at the scan rate of $50 \mathrm{mV} / \mathrm{s}$ in 0.2
M PBS (pH 3.0) as shown in Figure 8. The oxidation peak of MO at BCPE (at 1381mV) and PMOMCPE (at $1328 \mathrm{mV}$ ). An excellent enhancement of oxidation peak current was observed at PMOMCPE (2.7 times higher than BCPE). Shows the best electrocatalytic effect at PMOMCPE.

\section{Reproducibility and Stability}

The stability and reproducibility of PMO/CPE were the measures to estimate the sensing performance of the developed electrode. RSD of $\mathrm{I}_{\mathrm{pa}}$ was obtained $4.16 \%$ which indicates that the developed electrode is having acceptable reproducibility for the obtained result. This also shows that the no fouling of the electrode surface. The operational stability of the PMO/CPE remained 99\% of initial current with continues running even after 20 cycles. This indicates that the electrode having good stability.

\section{Conclusion}

This work demonstrates the ability of PMO/CPE for the electrochemical determination of CA. The best response of the sensor was achieved in $0.2 \mathrm{M}$ PBS pH 3.0. The oxidation peak current of $\mathrm{CA}$ was proportional to the concentration range from $1 \times 10^{-5}$ to $5 \times 10^{-5}$, and $6 \times 10^{-5}$ to $1.5 \times 10^{-4} \mathrm{M}$ with the low detection limit of $5.7 \times 10^{-7} \mathrm{M}$. Moreover, modified electrode shows excellent stability and reproducibility.

\section{Acknowledgement}

We gratefully acknowledge the financial support (KFIST) from the VGST, Bangalore under Research Project. No. KSTePS / VGSTKFIST (L1) 2016-2017/GRD- 559/2017-18/126/333, 21/11/2017.

\section{References}

1. Nawrot P, Jordan S, Eastwood J, Rotstein J, Hugenholtz A, et al. (2003) Effects of caffeine on human health, Food Additives and Contaminants 20(1): 1-30.

2. James JE (2004) Critical review of dietary caffeine and blood pressure: A relationship that should be taken more seriously. Psychosomatic Medicine 66(1): 63-71. 
3. Faupel C, Horowitz A, Weaver G (2013) The Sociology of American Drug Use, ( $3^{\text {rd }}$ edn.).

4. Kristjansson AL, Sigfusdottir ID, Frost, James JE (2013) Adolescent Caffeine Consumption and Self-Reported Violence and Conduct Disorder. Journal of youth and Adolescence 42(7): 1053-1062.

5. Cauli 0, Morelli M (2005) Caffeine and the dopaminergic system, Pharmacology 16(2): 63-77.

6. Fernandez PL, Martın MJ, Gonzalez AG, Pablos F (2000) HPLC determination of catechins and caffeine in tea: differentiation of green, black and instant teas. Analyst 125(3): 421-425.

7. Sharma V, Gulati A, Ravindranath SD, Kumar V (2005) A simple and convenient method for analysis of tea biochemicals by reverse phase HPLC. Journal of Food Composition and Analysis 18(6): 583-594.

8. Regan F, Shakalisava Y (2005) Rapid simultaneous determination of alkylxanthines by CZE and its application in analysis of pharmaceuticals and food samples. Analytica Chimica Acta 540(1): 103-110.

9. Wang A, Li L, Zang F, Fang Y (2000) Amperometric detection of three purine alkaloids following their separation by micellar electrokinetic capillary chromatography, Analytica Chimica Acta 419(2): 235-242.

10. Khanchi AR, Khayatzadeh Mahani M, Hajihosseini M, Maragheh, MG, Chaloosi M, et al. (2007) Simultaneous spectrophotometric determination of caffeine and theobromine in Iranian tea by artificial neural networks and its comparisonwith PLS. Food Chemistry 103(3): 1062-1068.

11. Lopez-Martınez L, Lopez-de-Alba PL, Garcia-Campos R, De LeonRodrıguez LM (2003) Simultaneous determination of methylxanthines in coffees and teas by UV-Vis spectrophotometry and partial least squares. Analytica Chimica Acta 493(1): 83-94.

12. Amare M, Admassie S (2012) Polymer modified glassy carbon electrode for the electrochemical determination of caffeine in coffee. Talanta 93: 122-128.

13. Carolina Torres A, Barsan MM, Brett CMA (2014) Simple electrochemical sensor for caffeine based on carbon and Nafion-modified carbon electrodes. Food Chemistry 149: 215-220.

14. Paradkar MM, Irudayaraj J (2002) A Rapid FTIR spectroscopic method for estimation of caffeine in soft drinks and total methylxanthines in tea and coffee. Journal of Food Science 67(7): 507-511.

15. Manjunatha JG (2017) Electroanalysis of estriol hormone using electrochemical sensor. Sensing and Bio-Sensing Research 16: 79-84.

16. Manjunatha JG, Deraman M, Basri NH, Talib IA (2018) Fabrication of poly (Solid Red A) modified carbon nano tube paste electrode and its application for simultaneous determination of epinephrine, uric acid and ascorbic acid. Arabian Journal of Chemistry (11): 149-158.

17. Manjunatha JG (2018) Highly Sensitive Polymer based Sensor for Determination of the Drug Mitoxantrone. Journal of Surface Science and Technology 34(1): 74-80.

18. Manjunatha JG (2018) A novel poly (glycine) biosensor towards the detection of indigo carmine: A voltammetric study. Journal of Food and Drug Analysis 26(1): 292-299.

19. Manjunatha JG, Deraman M, Basri NH (2015) Electrocatalytic detection of dopamine and uric acid at poly (basic blue B) modified carbon nanotube paste electrode. Asian Journal of Pharmaceutical and Clinical Research 8(5): 40-45.

20. Manjunatha JG, Deraman M, Basri NH, Mohd Nor NS, Talib IA, et al. (2014) Sodium dodecyl sulfate modified carbon nanotubes paste electrode as a novel sensor for the simultaneous determination of dopamine, ascorbic acid, and uric acid. Comptes Rendus Chimie 17(5): 465-476.

21. Manjunatha JG, Kumara Swamy BE, Mamatha GP, Ongera Gilbert, Chandrashekar BN, et al. (2010) Electrochemical Studies of Dopamine and Epinephrine at a Poly (Tannic Acid) Modified Carbon Paste Electrode:
A Cyclic Voltammetric Study. International Journal of Electrochemical Science 5: 1236-1245.

22. Mersal GAM (2012) Experimental and computational studies on the electrochemical oxidation of caffeine at pseudo carbon paste electrode and its voltammetric determination in different real samples. Food Analytical Methods 5: 520-529.

23. Nunes RS, Cavalheiro E (2012) Caffeine determination at a carbon fibre ultramicroelectrodes by fast-scan cyclic voltammetry. Journal of Brazilian Chemical Society 23(4): 670-677.

24. Sun JY, Huang KJ, Wei SY, Wu ZW, Ren FP (2011) A graphene-based electrochemical sensor for sensitive determination of caffeine. Colloids and Surface B 84(2): 421-426.

25. Spataru N, Sarada BV, Tryk DA, Fujishima A (2002) Anodic voltammetry of xanthine, theophylline, theobromine and caffeine at conductive diamond electrodes and its analytical application. Electroanalysis 14: 721-728.

26. Giribabu K, Haldorai Y, Rethinasabapathy M, Jang SC, Suresh R, et al. (2017) Glassy carbon electrode modified with poly (methyl orange) as an electrochemical platform for the determination of 4-nitrophenol at nanomolar levels. Current Applied Physics 17: 1114-1119.

27. Amare M, Admassie S (2012) Polymer modified glassy carbon electrode for the electrochemical determination of caffeine in coffee. Talanta 93: 122-128.

28. Zhang J, Wang LP, Guo W, Peng XD, Li M, et al. (2011) Sensitive differential pulse stripping voltammetry of caffeine in medicines and Cola using a sensor based on multiwalled carbon nanotubes and Nafion. International Journal of Electrochemical Science 6(4): 997-1006.

29. Degefu H, Amare M, Tessema M, Admassie S (2014) Lignin modified glassy carbon electrode for the electrochemical determination of histamine in human urine and wine samples. Electrochimica Acta 121: 307-314.

30. Uslu B, Ozkan SA (2007) Electroanalytical application of carbon-based electrodes to the pharmaceuticals. Analytical Letters 40(5): 817-853.

31. Beitollahi H, Sheikhshoaie I (2012) Electrochemical Behavior of Carbon Nanotube/Mn(III) Salen Doped Carbon Paste Electrode and Its Application for Sensitive Determination of $\mathrm{N}$-acetylcysteine in the Presence of Folic Acid. International Journal of Electrochemical Science 7: 7684- 7698 .

32. Manjunatha JG (2017) A new electrochemical sensor based on modified carbon nanotube- graphite mixture paste electrode for voltammetric determination of resorcinol. Asian Journal of Pharmaceutical and Clinical Research 10(12): 295-300.

33. Raril C, Manjunatha JG (2018) Sensitive and Selective Analysis of Nigrosine Dye at Polymer Modified Electrochemical Sensor. Analytical and Bioanalytical Electrochemistry 10(3): 372-382.

34. Raril C, Manjunatha JG (2018) Sensitive Electrochemical Analysis of Resorcinol using Polymer Modified Carbon Paste Electrode: A Cyclic Voltammetric Study. Analytical and Bioanalytical Electrochemistry $10(4): 488-498$

35. Faria EO, Lopes Junior ACV, Souto DEP, Leite FRF, Damos FS, et al (2012) Simultaneous determination of caffeine and acetylsalicylic acid in pharmaceutical formulations using a boron-doped diamond film electrode by differential pulse voltammetry. Electroanalysis 24: 11411146

36. Alizadeh, T, Ganjali MR, Zare M, Norouzi P (2010) Development of a voltammetric sensor based on a molecularly imprinted polymer (MIP) for caffeine measurement. Electrochimica Acta 5: 1568-1574.

37. Mersal GM (2011) Experimental and computational studies on the electrochemical oxidation of caffeine at pseudo carbon paste electrode and its voltammetric determination in different real samples. Food Analytical Methods 5: 520-529. 
38. Sanghavi BJ, Srivastava AK (2010) Simultaneous voltammetric determination of acetaminophen, aspirin and caffeine using an in-situ surfactant-modified multiwalled carbon nanotube paste electrode. Electrochimica Acta 55: 8638-8648.

ISSN: 2574-1241

DOI: $10.26717 / B J S T R .2018 .09 .001804$

JG Manjunatha. Biomed J Sci \& Tech Res

(C) This work is licensed under Creative

Submission Link: https://biomedres.us/submit-manuscript.php
39. Ghadimi H, Ramin MAT, Basirun WJ, Ab Aziz NJ, Norita M, et al. (2016) Electrochemical determination of aspirin and caffeine at MWCNTs-poly4-vinylpyridine composite modified electrode. Journal of the Taiwan Institute of Chemical Engineers 65: 101-109.

$\begin{array}{ll}\text { BIOMEDICAL } & \text { Assets of Publishing with us } \\ \text { RESEARCHES } & \text { - Global archiving of articles } \\ & \text { - Immediate, unrestricted online access } \\ & \text { - Rigorous Peer Review Process } \\ \end{array}$

